\title{
Computer based environmental studies in Lithuania
}

\author{
Vitalij Denisov \\ Klaipeda University \\ Lithuania \\ Justin Dillon \\ King's College London \\ United Kingdom
}

\begin{abstract}
This paper describes the development of university level interdisciplinary environmental studies curricula in Lithuania with an emphasis on the use of information technology. In order to set up the aims and content of the curriculum a model of the future specialist's activities has been developed. The objectives of the appropriate courses were formulated and the needs for curriculum development were subsequently determined. This led to the setting up of the European Union TEMPUS project 'Computer Based Environmental Studies in Lithuania (COBES-Lithuania)'.
\end{abstract}

Main conference themes: developing countries

Educational areas: higher education

Study topics: environment

Secondary keywords: case studies, curriculum development, database, interdisciplinary 


\section{ENVIRONMENTAL STUDIES IN SECONDARY SCHOOL}

To ecologically educate students is one of Lithuania's school reform priorities (for a description of the structure of the education system in Lithuania and of the three models of curricula for environmental studies in secondary school and in higher education, see [1]). This reform is to be achieved by integrating biology with the other science subjects and through extracurricular activities.

Three stages of development in the understanding of ecological problems can be discerned:

- 1-4 years Developing of a desire to be closely associated with the natural environment through work on 'The world around me', literature, excursions and horticultural work at school plots.

- 5-9 years More detailed acquaintance with the environment through study of botany, zoology, geography, biology and chemistry. The since 1993 newly introduced course 'The Earth as Man's Home' for grades 5 and 6 provides an eco-geographical orientation and plays a key role in developing ecological skills.

- 10-12 years Development of the idea of rational behaviour. The new ecology course for grade 10 serves as a methodological background for understanding the tensions between civilisation and biosphere, the concept of co-evolution, the anthropogenic factors in pollution and evaluation of the ecological law system. New syllabuses for general biology, genetics and all of the chemistry subjects deal with this as well.

\section{The Role of IT in the school curriculum}

By the end of the 1980s a special informatics course had been introduced in schools for grades 10-12. The course starts with the basic principles of computer arithmetic and logic, gives an introduction to computer elements and mainly covers the algorithm construction methodology and programming. The programming language commonly used is BASIC, only in a few schools is an introduction to programming in PASCAL provided. Because only a small number of schools is equipped with computers the course mentioned is more theoretical than practical.

Apart from computer science itself application of IT in the school curriculum is very limited. Although some institutions, like the Informatics and Programming Centre in Vilnius (the capital of Lithuania), have begun work in this field, the educational software market in Lithuania has not yet opened up. There is therefore a brisk demand for both educational software and for knowledge about the methodology of their implementation as a learning tool across the school curriculum. 


\section{ENVIRONMENTAL STUDIES IN HIGHER EDUCATION}

All Lithuanian universities educate students in environmental sciences in three categories of graduate degrees. It takes four years to receive a bachelor's degree and a further year to gain a master's degree. The Doctor's degree usually takes at least three more years after the master's degree. As a rule the undergraduate course includes fundamentals of biological sciences, mathematics, physics, humanities and also pedagogical-psychological courses, but the content and structure of the curricula significantly differ between different universities. Vilnius University preserves a tradition in biology teaching and environmental studies there are all biology biased. At Kaunas Vytautas Magnus University almost the same model of environmental education is adopted. The biological faculty of the Vilnius Pedagogical University trains teachers in two science subjects, major and minor. The interdisciplinary approach applied involves biology and a closely related science subject such as chemistry or agriculture. The biology students are only provided with an introductory computer science course. During the last few years some optional courses involving IT have been introduced (for further details see [2]).

As youngest higher education institution in Lithuania the University of Klaipeda has a good opportunity to introduce up-to-date education technologies because it is not hindered by conservative and inflexible natural science curricula. After the new Faculty of Natural Sciences had been set up in 1991 a process of interdisciplinary curriculum development was started. In order to be able to define aims and content of the curriculum a model was developed describing the future specialist.

The first stage in this process simply consisted of describing the student's basic abilities and skills [3]. These are necessary to be able to solve the basic problems in the core of the specialist's future professional activities. Typical tasks were identified and formulated by analyzing the activities of specialist ecologists in environmental protection and ecological monitoring, environmental education and research.

After having identified these basic skills and knowledge the requirements which a modern specialist ecologist must meet were formulated. It was concluded that graduate ecologists should:

- have good and up-to-date knowledge in the field of computer science;

- be able to use database, information and telecommunication systems;

- be able to use sensors to monitor experiments in progress;

- master the biometrics methods;

- be able to use and detail simulation models. 
The second stage in the formulation of the model consisted of the design of courses aimed at developing the abilities and skills identified in the first stage. Although a university's computerization programme had been started the following fundamental problems made it difficult to realize the ideal model in practice:

Methodological problems: Even within the groups of experienced university teachers and scientists there is a lack of experience in the field of computer use to support and enhance the learning process.

Technical and financial problems: Particularly the high costs and hardware requirements for the best commercial packages are prohibitive. Modern educational software requires IBM compatible PC 386 or higher models and the Windows 3.1 environment.

Educational software problems: The educational software market is not formed yet in Lithuania. The number of educational programs translated into Lithuanian is next to nothing.

When analyzing this situation it became clear that intensive use of IT in the curriculum would only be possible through international cooperation with appropriate universities and institutions in the European Union (EU). This triggered the TEMPUS project 'Computer-Based Environmental Studies in Lithuania'.

\section{THE TEMPUS PROJECT 'COBES-LITHUANIA'}

COBES-Lithuania started in 1993 as an EU TEMPUS project. The aim of the three-year project is to revise and improve interdisciplinary environmental studies curricula in secondary schools and universities with a particular emphasis on the use of IT to effect the changes. The project proposal was based on the curriculum model described above and on an organizational structure which had already proven itself in Bulgaria in the COBES-Bulgaria project. The cooperation involved ten partners from five countries: the management partners are Orfeus, Denmark; the University of Klaipeda, Lithuania; King's College London, UK and IPN, Germany. The project links with TEMPUS and other European and world wide projects, including GREEN, CoastWatch and CERES-DATA. 
The project activities are organized in three main tasks:

- Task 1 Analysis of the existing environmental studies curricula. Curriculum improvement and development through the use of advanced technologies.

- Task 2 Educational software adaptation and development.

- Task 3 River monitoring, data sampling and the establishment of a network for river pollution data exchange within the framework of the GREEN (Global River Environmental Education Network) methodology [4].

\section{Project Implementation}

Key elements in the process of project implementation are 'working conferences'. As the investigated area is interdisciplinary the project team involves both staff and students from different traditional disciplines. Next to the task activities mentioned another important objective of these conferences is therefore to establish effective relations between partners and participants, to bring together their ideas and experience in order to form a common vision of the project goals and to tie the project by common efforts. Three working conferences in Klaipeda (October 1993), Denmark (March 1994) and Germany (April 1994) have done just that.

The step-by-step implementation of all three tasks was discussed and agreed during the Klaipeda conference. The revisions of existing curricula (Task 1) at Klaipeda University and Kaunas University of Technology (the second Lithuanian partner) were described and changes clearly indicated. The practical introduction of IT into the environmental curricula has led to the following innovations:

- An introductory course in the use of the computer as a practical tool for basic tasks such as word processing, data representation, calculations and graphics.

- An optional course in problem solving with practical PASCAL programming.

- The use of database and data exchange software tools.

- The modernization of more specialized courses based on selected software:

Meteorology and climatology: The software chosen is 'Probe', an advanced tool for processing and analyzing digital images from satellites, radar, etc., with special educational facilities such as pixel classification and the ability to display pixel values within a certain selected area.

Ecological monitoring: The software 'Umweltatlas' is written in MSDOS using the hypertext system IBM Linkway and can be used for collection and analysis of data on water quality in rivers following the GREEN methodology. 
Biometrics: The package 'Bioview for Windows' provides a three dimensional database representation which allows collection and analysis of data in terms of three interacting variables.

Ecological modelling: The flexible simulation tool 'Dymos' is designed for the creation and investigation of mathematical models which make it easy to investigate the connection between formalized expressions and the consequences of the model. Both the equations and the parameters may be changed interactively by the user. A Windows application 'Model Builder' enables students to acquire skills in communication and handling of information since they can present and explain their models on the screen.

Another important idea is that the project, just as COBES-Bulgaria, should not just import ideas from the EU, but should also intensify cooperation between Lithuanian universities. To realize this a strong link has been established between the universities in Klaipeda and Kaunas. The activities planned include:

- The establishment of Open Studies to exchange staff and students.

- The development of modules on Ecotechnics and Geographical Information Systems (GIS) which are shared by both universities.

- The joint production of both printed and computer based materials for teacher training courses.

Task 2 is done in three stages: getting acquainted with software from the European educational market, discussion about the needs of the user and then the final selection of candidates for adaptation. The main criteria for the selection are:

- Curriculum use: does the software fit the needs of the curriculum model proposed above and does it supplement the other project tasks?

- Educational features: does it provide explanatory feedback and other pedagogical benefits for both teachers and students?

- Technical features: is it easy to meet the technical requirements considering the existing (or planned) technological level at Lithuanian schools and universities?

Getting acquainted with the software: some of the software selected (Dymos, Bioview) has already been used at the universities without special adaptation. The reason is that it gave the opportunity to collect necessary experience in advance before final versions are prepared.

The second stage of software adaptation and modification is restricted to the translation of printed and computer based texts into Lithuanian and to 
supplementing the programs with special features such as data input-output from/to different formats. The main programming job here is to prepare Windows versions of programs written for the MS-DOS environment. To make the job faster it was decided to involve students in this activity from the very beginning of the project. In a 4-month stay at King's College London and Orfeus the $\beta$-versions of 'Umweltatlas' and 'Probe for Windows 3.1' have been prepared. The experience gained should also be used for producing original Lithuanian educational software. So the task for the final phase is to plan the kernel of an educational software development team in Lithuania.

The river monitoring activities (Task 3) are planned as an action research programme which will cover the main phases of any ecological investigation:

- An introduction to the matter, defining the environmental problem;

- Field work, sampling and data collection;

- Presenting the results, interpretation and identification of the possible causes;

- Setting up an action strategy and understanding the changes needed in a local society to turn it to a sustainable development.

The activities are based on the GREEN methodology with the intention to develop a national water quality data exchange network and, finally, to join the international GREEN network. Both the initial training of staff and students and the identification of pilot centres were made through the working conferences and the mobility programme. The textbook Nearby Rivers and supplementary materials have been translated, adopted and disseminated among teachers involved in the activities. Regular measurements in the Klaipeda and Kaunas regions (rivers Dane, Smeltele, Nemunas and Neris) started in late 1994 following the arrival of additional portable test kits. Software support for this task (a Lithuanian version of 'Umweltatlas') will be provided.

To support the tasks mentioned centres have been established both at Klaipeda University and Kaunas University of Technology. The centres allow sharing of the limited number of equipment received and will also play a coordinating and propagating role in the regional area.

\section{INITIAL RESULTS AND PERSPECTIVES}

No doubts the COBES-Lithuania project has had a significant influence on the curricula and educational activities in the two Lithuanian universities. By the end of the first year of implementation more than 20 teachers and students were trained/updated abroad; a number of courses was analyzed and improved; relevant software items were selected and the localisation of both software and teaching materials was started. Pilot river monitoring was also done. 
It is however our intention that the project, just as COBES-Bulgaria, should also be relevant outside the university system and must have long term consequences for the whole educational system in Lithuania. To achieve this and to ensure the further development after the project finishes objectives for future activities have been formulated:

- The collaboration already established will be enhanced and new Lithuanian partners will be involved. In order to strengthen the impact on the Lithuanian secondary school system it is planned to link the project with an international (Danish-Lithuanian) training programme for Lithuanian high school teachers. Three training courses for Lithuanian school teachers have been arranged in Klaipeda and in Kaunas. These interdisciplinary courses will cover the subjects connected with COBES activities: river monitoring, seawater monitoring and the evaluation and use of educational software.

- International relations should be intensified as well. It is planned that the Lithuanian results and environmental data obtained will be shared internationally in projects including GREEN, CoastWatch and the UGIS (University Geographical Information Systems) Network. The link with another TEMPUS project: 'The Development of a New Curriculum for Teaching Computer Networking in Lithuania'-may help in making software adaptation easier and the dissemination of the adapted software more widespread.

- To enlarge the existing small market for educational software in Lithuania and to stimulate the process of software development it is planned to join the EPES (European Pool of Educational Software) project supported by the EU Task Force programme. Project partners will also continue the joint software development mentioned above.

- The supporting centres are to play a more essential role in all the activities. Besides training of teachers and river monitoring support the centres will take the responsibility for dissemination activities such as the production of diskettes and CD-ROMs, and for the printing of teaching materials and manuals. They will also offer some other pedagogical and technical services in order to ensure quality, common standards and compatibility of both software and hardware to be purchased and used at schools. 


\section{REFERENCES}

1. Denisov V. (1994) Models of Environmental Education in Higher Educational System of Lithuania, in Modelle zur Umwelterziehung in der Bundesrepublik Deutschland. Band 5: Umwelterziehung in den neuen Ländern. DGI/IPN, Kiel, pp. 183-99.

2. Bosler. U., Denisov, V., Dillon, J. and Højsholt-Poulsen, L. (1994) Computer Based Environmental Studies in Lithuania (COBES-Lithuania). Proceedings of the Initial Working Conference, Klaipeda, October 1993 (available from Orfeus, Skaering Skolevej 202, DK-8250 Egaa, Aarhus, Denmark).

3. Bokans, J. J. (1989) Aims for the training of students in the field of computer application to physical research, in Methods and devices for physical research. Riga University Press, Riga, pp. 192-200.

4. Prigge, S. (in co-operation with Tissler, B.) (1994) Nearby Rivers. IPN, Kiel and Amt für Schule: Hamburg (available from IPN, Olshausenstr. 62, D24098 Kiel, Germany). 